This is a self-archived version of an original article. This version may differ from the original in pagination and typographic details.

Author(s): Ruoranen, Minna; Antikainen, Teuvo; Eteläpelto, Anneli

Title: Surgical learning and guidance on operative risks and potential errors

Year: 2017

Version: Accepted version (Final draft)

Copyright: (c) 2017, Emerald Publishing Limited

Rights: In Copyright

Rights url: http://rightsstatements.org/page//nC/1.0/?language=en

Please cite the original version:

Ruoranen, M., Antikainen, T., \& Eteläpelto, A. (2017). Surgical learning and guidance on operative risks and potential errors. Journal of Workplace Learning, 29(5), 322-338.

https://doi.org/10.1108/JWL-12-2016-0104 


\title{
Surgical learning and guidance on operative risks and potential errors
}

\begin{abstract}
Within the framework of learning from errors this study focused on how operative risks and potential errors are addressed in guidance to surgical residents during authentic surgical operations. The overall purpose is to improve patient safety and to diminish medical complications resulting from possible operating errors. Further in the process of the optimal contexts for instruction aimed at preventing risks and errors in the practical hospital environment was evaluated.
\end{abstract}

The five authentic surgical operations were analyzed, all of which were organized as training sessions for surgical residents. The data (collected via video-recoding) were analyzed by a consultant surgeon and an education expert working together.

The results showed that the risks and potential errors in the surgical operations were rarely addressed in guidance during operations. The guidance provided mostly concerned technical issues, such as instrument handling, and exploration of critical anatomical structures. There was little guidance focusing on situation-based risks and potential errors, such as unexpected procedural challenges, teamwork and practical decision making. The findings showed that optimal context of learning about risks and potential errors of surgical operation is not always the authentic operation context.

The study was conducted in an authentic surgical operation-cum-training context. The originality of the study derives from its focus on guidance related to risk and error prevention in surgical workplace learning. The findings can be used to create a meaningful learning environment - including powerful guidance - for practice-based surgical learning, maximally addressing patient safety, but giving possibilities also for other training options.

Key words: Learning from errors, guidance, surgical training, operative risks, learning environment 


\section{Surgical learning and guidance on operative risks and potential errors}

\section{Introduction}

Learning from errors at work has been increasingly discussed in the recent literature on workplace learning (Dochy et al., 2011; Harteis and Bauer, 2014). Understanding the processes of learning from errors, some of the more general theories on professional and practice-based learning have been considered relevant as a starting point for elaborating learning from errors. Harteis and Bauer (2014) have suggested three different notions, which could contribute to our understanding on the processes of learning from errors. First, they discuss how the perspective of experiential learning (Kolb, 1984) could contribute to our understanding of learning from errors. In this approach, errors can be understood as concrete experiences which trigger learning through reflection. From the experiential learning perspective, errors are seen as specific incidents of concrete experiences that diverge from prior knowledge (Bauer and Gruber, 2007; Bauer and Mulder, 2007, 2008). Learning from errors through experiential learning has also been defined as negative knowledge. This is understood as experiential knowledge about what is wrong, about what not to do, and about the limitations of one's own knowledge, skills or cognition (Gartmeier et al., 2017). Such knowledge is vital in medical practice.

Second, theories of the reflective practitioner (Schön, 1983) and transformative learning (Mezirov, 1991) have contributed to a more comprehensive understanding of the nature of reflection, needed for learning from error. Reflection understood as a conscious, volitional process of interpreting and making sense of experiences enables correction of distortions in one's beliefs and errors in problem solving. Reflection can also mean performing root-cause analysis to identify the probable causes of an error (Bauer and Mulder, 2007). Such root-cause analysis is needed for the purposes of error and risk prevention, such as in medical practice where patient safety is the standard goal of medical treatment and operations (Aspden et al., 2004). Both experiential learning and reflective processes can profit from social and collectively shared processes of group or organizational learning (Billett 2006; Tucker and Edmonson, 2003). However, errors, as well as learning from them, can only be analyzed in a specific professional, local or 
cultural context (Gartmeier et al., 2017). This is also important when seeking and developing alternative action strategies within the related organizational context (Bauer and Mulder, 2017).

Third, the concept of deliberate practice (Ericsson 2006) is also seen relevant for learning at work. Deliberate practice implies efforts to improve individual performance and capabilities by analyzing and reflecting on one's past performance and consciously practicing tasks that have not yet been mastered and thus manifest as erroneous (Harteis and Bauer 2014). Such deliberate practice is needed for the attainment and maintenance of expert performance, and the goals of learning need to be specified with the guidance and supervision of a senior domain expert. In surgical learning, senior surgeons have a crucial role in the prevention of operative risks and potential errors. This role is even more important in training situations where novice surgeons are trained in authentic surgical contexts.

So far, most empirical studies on learning from errors have been addressed within the context of workplace learning and thus conducted with experienced professionals as subjects. However, less research has been done on the initial phase of the professional and practice-based learning of novices, especially in high-risk work, such as surgery. Instead, Cattaeno and Boldrini (2016) elaborated learning from errors in commercial vocational education using video-recorded worked-out examples of correct behavior and analysis of errors. They found no difference in declarative knowledge; instead learning from errors was more effective in terms of detailed procedural knowledge and anticipatory knowledge about possible errors to be avoided. Developing /learning such anticipatory knowledge on avoidable errors is vital in medical education in order to guarantee patient safety, which is a major goal in medicine (Aspden et al., 2004). In practical medical learning settings, avoidable errors are present (implicit / embedded) as risks and possible errors. Learning to recognize and avoid these should be supported by instructional activities and guidance during medical operations taking place in authentic situations.

Special challenges for guidance in authentic medical operations are present in surgical training where guidance interaction is embedded in real-life conditions with its timepatient-, and disease specific constraints. This study aims to contribute to the discussion 
on the role of in-situ guidance in learning, both to avoid potential errors and to take into consideration risks in high-risk work activities, such as surgical operations.

\section{Risks and errors in surgery}

Risk evaluation, risk management, and patient safety are bound up with the success of surgery or of any medical treatment. There are indications that the development of patient safety may have stalled. For example, serious complications in very common operations, such as cholecystectomy, have stayed at the same level (5\%) for a couple of decades (Antikainen et al., 2010; Agresta et al., 2014; Fried et al., 2005; Park et al., 2010). A cholecystectomy is a surgical procedure which is performed done to cure a symptomatic gallbladder disease and which includes the surgical removal of this organ. Nowadays the most favored technique for doing this is minimal invasive surgery, also often referred to as laparoscopic surgery, in which the gallbladder is removed through very small $(5 \mathrm{~mm}$ to $20 \mathrm{~mm}$ ) abdominal skin incisions. In total, four or five skin incisions are needed for the 'instrument gates' (trocars) through which the instruments (cutting and dissecting instruments and camera) are inserted at the operation site. The gallbladder is anatomically situated in the upper abdominal cavity and is attached to the liver by fibrous tissue, blood vessels and a bile duct (named the cysticus and further on choledochus). This abdominal region is also backed by the intestines and major blood vessels.

This common, but demanding surgical procedure is sensitive to well-reported risks, which may give rise to surgical errors, and even fatal complications. These complications may have been caused by human errors and/or system failures. In the case of laparoscopic cholecystectomy (LAP chole), such failures have been divided into twenty failure types (Silvennoinen et al., 2015), all of them tending to increase the risk of surgical complications. It is vital that these failure types and their recognition should be included in surgical residents' in vivo training, so that critical aspects are recognized and utilized for training purposes.

So far, surgical practice-based in vivo training has been based on the traditional apprenticeship model, in which the residents (trainees) learn by participating, operating under the guidance of a proficient surgeon (trainer). The trainer has an important dual role, as a domain expert, and as a teacher. As an expert in the domain, the trainer is 
required to provide knowledge on typical requirements and standards, and also on how to avoid risks and errors (Breckwoldt et al., 2014; Silvennoinen et al., 2015; Wenger, 1998). The trainer is expected to support the trainee's actions so that the trainee can reach a higher level of performance than could be reached by working alone. One of the most important guidance tasks is to teach trainees how to recognize and deal with possible risks and errors, and how to correct erroneous actions (Billett, 2016; Harteis and Bauer, 2014).

So far there have been relatively few studies on the quality of guidance, or on acts of guidance during in vivo training, especially in the field of potential errors and risk prevention. Sutkin et al., (2014a, 2014b) investigated verbal and non-verbal guidance interactions in surgical training. They found that for the most part non-verbal (physical) guidance was used, but that this was often accompanied by speech. Blom et al., (2007) analyzed and categorized verbal acts of explanation and guidance during surgical in vivo training. They found that the most common themes in instructive communication involved procedure-related matters, the location of instruments, and the patient's anatomy and pathology. There is no doubt that guidance should focus on these issues as learning goals. Nevertheless, it can be expected that the guidance will gain clinical relevance and become more meaningful if it also includes risk evaluation, risk management, and failure prevention. So far, knowledge is lacking on whether or how often the (mostly invisible) risks and failures faced during surgical procedures (such as LAP chole) are addressed in practical training. It also remains unknown how they are utilized in the guidance given during authentic operations.

This study focused on how operative risks and potential errors are utilized as instructional elements within the guidance-oriented interactions that take place during authentic surgical operations. The overall purpose is to improve patient safety and to diminish medical complications resulting from possible operating errors. Further, learning contexts that appear to be optimal in forestalling risks and errors in the practical hospital environment were evaluated.

\section{Practical training in surgical learning}

In Finland, after graduating from medical school, medical doctors (physicians) may choose any medical speciality and begin working and training as residents. All the training programs for surgical specialities last six (6) years. The first two-year period is 
spent in a central (teaching) hospital, and the following four-year period is spent in a university hospital. While working as residents, these graduate doctors function simultaneously in the dual (and sometimes confusing) role of professional and trainee. The residents participating in this study were in their first two-year training period and in the abdominal surgery training phase.

In medical education, and especially in surgical training, "learning by doing" continues to be a common practice (Dornan and Teunissen, 2014). This kind of practice-based learning occurs in a context that offers learners opportunities to participate and to reflect actively during tasks and interactions, and to be supported while doing so (Billett, 2016; Lave and Wenger, 1991). For learners, practice-based learning is a matter of observation, imitation, participation, and gaining personal experience during authentic work processes (Collins et al., 1989). Learning also occurs via social interaction with peers, co-workers, and trainers or mentors. Interactive talk during guidance plays an important role in the apprentice's learning (Billett, 2016; Gowlland, 2014; Koskela and Palukka, 2011; Naweed and Ambrosetti, 2015). For the trainers, practice-based learning means sharing understandings, interpreting meanings, providing insights into work procedures, and making overt the hidden knowledge that the trainee may not be able to acquire alone. It is especially important for trainers to make their own reasoning transparent, to think aloud, and to listen while learners share their thoughts. It is also necessary to have direct guidance-oriented interactions (whether verbal or nonverbal) and physical guidance, so that practice-based skills may be acquired in learning-by-doing settings (Billett, 2006; Smith et al., 2004; Sutkin, 2014a, 2014b).

In practice settings, guidance plays an important role in organizing learning and in helping the trainees to progress from being a novice towards becoming an expert (Sheehan and Higgs, 2013). The trainer's teaching and guiding methods have been described as (i) focusing the attention of learners on the salient features of the tasks, (ii) monitoring the degree of improvement, and (iii) using different types of demonstrations (Breckwoldt et al., 2014; Ingold, 2000). The trainer does not so much directly instruct the trainee; rather, he/she directs the attention of the trainee to relevant features, including the potential risks and failures present in the operation. This is what Ingold (2000) defines as the process of education of attention, referring here to the scaffolding constructed to direct the actions of apprentice dentist (Weddle and Holland, 2010). For their part, 
Breckwoldt et al. (2014) see the trainer as a "person-in-the-shadow," highlighting the special role of the trainer in the apprentice's in vivo training. Becoming a competent surgeon in a patient-safe way requires deliberate guidance-oriented interaction, in which attention is paid to the risks and possible errors related to the operation. The interaction may include monitoring and evaluating the completion of the action, and demonstrations on how to operate safely in different situations. Acts of guidance of this kind, which take place within guidance-oriented interactions between the trainer and the trainee, are critical for enhancement of the trainee's performance.

Operating together with the senior surgeon is an effective way to learn surgical skills and to become a competent professional (Kilminster and Zukas, 2005; Ruoranen, et al., 2013; Spaan et al., 2015). One role of the trainer is to design systematic practices which will improve the trainee's surgical skills and professional competencies on a step-by step basis (Billett, 2006; Breckwoldt et al., 2014; Harteis and Bauer, 2014). Such endeavors require a more elaborated understanding of surgical in vivo training, including the training given for the laparoscopic cholecystectomy (LAP chole) operation addressed in this paper.

Previous studies have shown that LAP chole and other surgical operations include various risks and potential errors (Catchpole et al., 2006; Silvennoinen et al.2015). Silvennoinen et al. (2015) analyzed risks and failures in LAP chole operations. The categories of risks and failures were related to the organizational culture, patient anatomy and physiology, and situational factors. In addition, human errors were classified as technical and non-technical errors. Although these findings describe risks and failures at the general level, they do not provide practical guidelines for surgical learning and guidance on operative risks and potential errors. In addition, there has been insufficient discussion on the learning contexts that may be optimal for recognizing and avoiding errors, or on how the learning in question could be based on a range of instructional methods and resources outside the operating theater. There is a need for a comprehensive set of guidelines on possible operative risks and errors, plus evaluation of the optimal contexts for achieving learning on risks/errors from a workplace learning perspective. This is necessary, since addressing all possible risks would take up too much time during an authentic operation. 


\section{Research task and questions}

This study focused on the guidance-oriented interactions for risk prevention that occurred during authentic day-surgical (typical, routinely performed, and elective) LAP chole operations. Such operations are performed by a medical team consisting of a resident (trainee) and a proficient surgeon (trainer), along with the nursing team. This study investigated the adequacy of guidance relating to the recognition, prevention, and management of operative risks and potential errors. In addition, the study considered the kinds of risks and errors that should be addressed both within and outside the authentic operation context, for example in simulation environments.

The research questions were framed as follows:

1. How are potential errors and risks addressed in guidance-oriented interactions between the trainer and the trainee during authentic surgical laparoscopic operations?

2. For training purposes, which risks and potential errors should be addressed during the actual operation, and which of them could be learned outside the operating theater?

The findings are discussed from the respective of how to construct effective and patient-safe surgical training environments in hospitals.

\section{METHODS}

\section{Data collection}

The data consisted of video recordings (including audio) of five authentic elective day-surgery laparoscopic cholecystectomy (LAP chole) operations. The recordings were made by the first author using four complementary cameras simultaneously (see Figure 1). These covered the operating field and the operating team from the following perspectives: (i) the actions of the trainee and trainer (viewed from the front) (upper left in Figure 1), (ii) hand motions viewed from above the operating table (upper right), (iii) a panoramic view of the entire surgical team (4-6 persons) in the operating theater (OT) (lower left), and (iv) the laparoscopic camera view showing the operating field (lower 
right) (see also Silvennoinen et al., 2015). The four video recordings were synchronized on one screen so that the analysis could be conducted using all four camera angles (Figure $1)$.

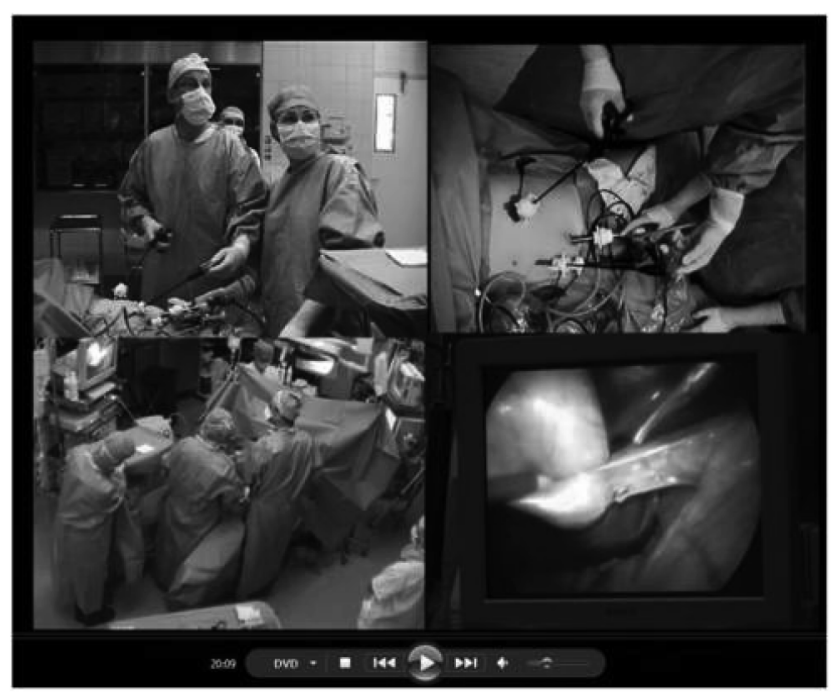

Figure 1. The screen including four synchronized video camera angles

All the video-recorded operations were medically successful, and the patients recovered normally. In each operation, a trainer was working in pairs with a trainee. Moreover, the operation had been designated as a training session for the trainee. This is the practice in most Finnish hospitals: a team consisting of a resident (trainee) and a senior surgeon (trainer) is always expected to promote learning when the two are working together. The recorded operations were guided and supervised by three different trainers: two consultant (gastroenterology) surgeons, and one intermediate-level resident. The nursing personnel of the operating teams varied from operation to operation.

The duration of the analyzed video recordings ranged from 43 minutes to 2 hours and 3 minutes (see table 1). In two of them (patient 1 and 2) the trainee began the operation; however, after problems arose, the trainer continued, detaching the gallbladder. In one of them (patient 3) the trainer conducted almost the entire operation; the trainee only closed the incisions. In one of them (patient 5) the trainee conducted the entire operation under the guidance of the trainer. 
Table 1. The patient, operation data (duration of the different phases), trainees and trainers of the authentic LAP chole operations analyzed.

\begin{tabular}{|c|l|l|l|l|l|l|l|}
\hline Patients & \multicolumn{3}{|l|}{ Duration of the phases (hours:minutes:seconds) } & Trainees & Trainers \\
\cline { 2 - 7 } & $\begin{array}{l}\text { 1.Preparing } \\
\text { for the } \\
\text { operation }\end{array}$ & $\begin{array}{l}\text { 2.Creating the } \\
\text { pneumo-perito } \\
\text { neum and } \\
\text { placing the } \\
\text { trocars }\end{array}$ & $\begin{array}{l}\text { 3.Removing } \\
\text { the } \\
\text { gallbladder } \\
\text { operation } \\
\text { phase) }\end{array}$ & $\begin{array}{l}\text { 4.Final check } \\
\text { and closure of } \\
\text { the incisions }\end{array}$ & Total & & \\
\hline $\mathbf{1}$ & $0: 01: 07$ & $0: 09: 07$ & $0: 22: 03$ & $0: 11: 00$ & $0: 43: 10$ & Mary & Kim \\
\hline $\mathbf{2}$ & $0: 00: 55$ & $0: 07: 00$ & $0: 46: 10$ & $0: 12: 40$ & $1: 06: 45$ & Andrea & Kim \\
\hline $\mathbf{3}$ & $0: 01: 04$ & $0: 06: 10$ & $0: 27: 43$ & $0: 05: 51$ & $0: 40: 48$ & Alice & Jill \\
\hline $\mathbf{4}$ & $0: 03: 00$ & $0: 11: 03$ & $0: 45: 03$ & $0: 12: 34$ & $1: 11: 40$ & Andrea & Peter \\
\hline $\mathbf{5}$ & $0: 02: 10$ & $0: 09: 10$ & $1: 42: 10$ & $0: 09: 48$ & $2: 03: 18$ & Alice & Peter \\
\hline
\end{tabular}

\section{Data analysis}

The analysis of the present data (i.e. video-recordings of authentic laparoscopic operations) were guided by knowledge of possible errors and risks drawn from the fields of education and medicine. Previously, the same video-recorded operations (research data) had been analyzed for another study (Silvennoinen et al., 2015) by three consultant surgeons, who focused on the errors and risks related to the standard phases of the LAP chole operation. This produced a general framework in which four different sequential phases were differentiated: i) preparing for the operation, ii) creating the pneumoperitoneum and placing the trocars, iii) removing the gallbladder (operation phase) and iv) final check and closure of the incisions (Silvennoinen et al., 2015). In the present study, the same sequential phases were used. However, the failure types identified in the previous study were not utilized, as Silvennoinen had categorized them from a different perspective (i.e. technical vs. non-technical risks/errors).

For the purposes of this study, one consultant surgeon, who had an additional specialization in medical education, worked with the first author, who has a background in medical education. This team watched the videos several times while engaging in dialogical discussion. The educational specialist wrote up notes on the discussions. Any points of disagreement were clarified together. In the first round of dialogue, a description of the original videotaped operation conducted by a trainee and a trainer was produced 
(see Table 1 column i). In the second round of the dialogue, the consultant surgeon assessed and told the educational specialist on what grounds the situation required special attention with respect to possible errors and risks (Table 1 column ii). Based on the second-round assessment, the consultant surgeon conducted a task-specific assessment of guidance related to possible errors and risks provided by the trainer (Table 1 column iii). The next phase of the analysis focused on the need and identification of the act of guidance in order to prevent and cope with the possible errors and risks present in the situation (Table 1 column iv). In this phase, the 110 acts of guidance related to possible risks and errors were specified. The consultant surgeon and education specialist conducted this analysis together through dialogical discussion. Table 2 gives an example of the data analysis of one episode lasting about 5 minutes.

Table 2. An example of the data analysis, based on the consultant surgeon's verbal assessmentu

\begin{tabular}{|c|c|c|}
\hline $\begin{array}{l}\text { Verbal assessment by the consultant } \\
\text { surgeon }\end{array}$ & $\begin{array}{l}\text { Aspects requiring attention } \\
\text { in order to avoid } \\
\text { risks/errors }\end{array}$ & $\begin{array}{l}\text { Corresponding act of guidance } \\
\text { (identified in the interaction) or } \\
\text { guidance omitted }\end{array}$ \\
\hline $\begin{array}{l}\text { Just the first glance tells you that this is not } \\
\text { the simplest operation. The trainer talks } \\
\text { about this observation. }\end{array}$ & $\begin{array}{l}\text { Risk and potential errors } \\
\text { concerning individual } \\
\text { variation in the patient's } \\
\text { pathology and anatomy }\end{array}$ & $\begin{array}{l}\text { Diagnostic tricks, tips, and } \\
\text { suggestions provided by the team } \\
\text { Risk identified. }\end{array}$ \\
\hline $\begin{array}{l}\text { In that tissue package there can be a blood } \\
\text { vessel; it looks so tight, you have to look at } \\
\text { it carefully. The trainer does not pause in } \\
\text { what he is doing. }\end{array}$ & $\begin{array}{l}\text { Risk of damaging the } \\
\text { patient's tissues and critical } \\
\text { vessels }\end{array}$ & $\begin{array}{l}\text { Lack of explanation of the visual } \\
\text { sightings: no tips provided on the } \\
\text { tissue's appearance, or } \\
\text { distinctions between different } \\
\text { kinds of tissues and structures. } \\
\text { Risk not identified. }\end{array}$ \\
\hline $\begin{array}{l}\text { The resident moves to dissect the tissues at } \\
\text { a point too low down. The trainer guides } \\
\text { her to dissect in the right place. }\end{array}$ & $\begin{array}{l}\text { Risk of damaging the } \\
\text { patient's anatomical } \\
\text { structures through dissection } \\
\text { of the tissues in the wrong } \\
\text { anatomical place (i.e. not in } \\
\text { the optimal and safest way) }\end{array}$ & $\begin{array}{l}\text { The trainer verbally guides the } \\
\text { resident to operate (dissect) in the } \\
\text { correct anatomical site. } \\
\text { Risk identified. }\end{array}$ \\
\hline $\begin{array}{l}\text { The trainer should point out why he is using } \\
\text { one kind of instrument or cutting method } \\
\text { rather than another. The trainer does not } \\
\text { indicate to the resident that he is cutting } \\
\text { several small pieces of tissue at a time. }\end{array}$ & $\begin{array}{l}\text { The selection and use of } \\
\text { specific instruments related } \\
\text { to the patient's anatomical } \\
\text { characteristics }\end{array}$ & $\begin{array}{l}\text { The trainer does not address } \\
\text { instrumentation at all. } \\
\text { Risk not identified. }\end{array}$ \\
\hline
\end{tabular}


For the first research question on how potential errors and risks are addressed in guidance, the acts of guidance which were assessed as necessary for preventing and coping with possible errors and risks were noted in the five operations analyzed. Thereafter, errors and risks were documented cross-case based (across the operations) and similar ones assigned to the same category using thematic analysis (Brown \& Clarke, 2006). These were further categorized into (i) those present in the guidance interaction provided by the trainer (senior surgeon) and trainee (resident), and (ii) those which not present.

To answer the second research question on which risks and potential errors should be addressed during the actual operation and which of them could be learnt outside the operating theater, 110 risks and potential errors were categorized by the consultant surgeon and the education specialist into two categories, namely (i) optimally trained within the OT environment, (ii) optimally trained outside the OT environment. The categories were based on whether or not well-established training methods or facilities exist outside the operating theater that would allow risk prevention to be addressed with adequate reality. These methods would include text- and video-based training materials, hospital protocols concerning procedures and their management, advanced simulation equipment, and technical facilities for specific surgical skill training (http://www.ksshp.fi/en-US/Professionals/Education_and training/Center_of_Medical

\section{Expertise).}

The assessment also considered aspects of cost-effectiveness in the training. The challenges here would involve, for example, difficulties in organizing hands-on training in real operations within the hospital, lack of guidance competences among senior surgeons (trainers), and ethical considerations regarding patient safety. The evaluation of this aspect was conducted by an experienced consultant surgeon who was responsible for medical education in the hospital in question. In addition, researcher triangulation was utilized in the evaluation. 


\section{FINDINGS}

The findings are presented in the order of the research questions. First, we report how potential errors and risks were addressed in the interactions between the trainer and the trainee during authentic surgical laparoscopic operations. Second, we report the findings on which potential errors and risks should be addressed during authentic operations, and which could be addressed otherwise.

For the purposes of our first research question, the 110 risks or potential errors were categorized into 41 different acts of guidance after which it was studied how these were addressed during the operation (see Table 3). The typical content of the guidance related to risks and errors can be described as follows. In the first phase of the LAP chole operation the trainer and the trainee shared the patient's clinical information and symptoms, the presuppositions for the operation, risk assessment, and the indicators for operating on the patient. In the second phase, they focused on filling the abdominal cavity with gas. The trainer passed on various diagnostic tricks and tips regarding the job in hand; for example, he shared ideas based on a first look at the personalized anatomy of the patient. In the third phase of the operation the trainer paid attention to possible errors and risks, sharing tips regarding the appearance and forms of the tissues. He identified structures for which caution was required, demonstrating how to dissect the anatomical structures in the safest way. At this point the trainer gave considerable support to the trainee on handling the instruments. In the final phase of the operation the trainer demonstrated inspection of the abdominal cavity, indicating how to prepare for potential damage; he also demonstrated means to staunch bleeding. 
Table 3. Acts of guidance (41 in total) related to possible risks and errors pointed out within the four phases of the five LAP chole operation

\begin{tabular}{|c|c|}
\hline $\begin{array}{l}\text { Acts of guidance related to possible } \\
\text { risks and errors which were present in } \\
\text { the guidance provided }\end{array}$ & $\begin{array}{l}\text { Acts of guidance related to possible risks and errors which } \\
\text { were not present within the guidance provided }\end{array}$ \\
\hline \multicolumn{2}{|l|}{ PHASE 1 Preparing to operate } \\
\hline $\begin{array}{l}\text { Clinical information concerning the } \\
\text { patient (e.g. indications, the patient's } \\
\text { symptoms, overall risk assessment of the } \\
\text { operation) }\end{array}$ & $\begin{array}{l}\text { Ergonomic quality: position of the surgeon and assistant (e.g. } \\
\text { height of the operating table, location of monitors, gaze } \\
\text { direction) } \\
\text { Ensuring the theoretical knowledge and skills needed for this } \\
\text { particular operation } \\
\text { Principles of operating if problems or emergency situations occur } \\
\text { Selection principles regarding the instruments required } \\
\text { Collaboration between the entire operating team } \\
\text { Potential checklist }\end{array}$ \\
\hline \multicolumn{2}{|c|}{ PHASE 2 Creating the pneumoperitoneum and placing the trocars } \\
\hline $\begin{array}{l}\text { Filling the abdomen with gas ( }+ \text { related } \\
\text { technology, and amount of gas) } \\
\text { Diagnostic tricks, tips, suggestions based } \\
\text { on an initial glance }\end{array}$ & $\begin{array}{l}\text { Testing and installation of the venting needle } \\
\text { Search for potential bleeding sites } \\
\text { Different kinds of trocars and how to use them } \\
\text { Blind installation of the first trocar } \\
\text { Paying attention to the personal anatomy of the patient, seeking } \\
\text { to create optimal conditions for the operation } \\
\text { Placing the trocars, taking into account the personal anatomy of } \\
\text { the patient (including mounts, body shape, intra-abdominal fat, } \\
\text { previous scars, anatomy related to the liver and gall bladder) } \\
\text { Avoiding the superficial blood vessels by illuminating these } \\
\text { structures through the skin } \\
\text { Placing the trocars in optimal relation to each other } \\
\text { The importance of the issues for subsequent fluency and safety in } \\
\text { the operation }\end{array}$ \\
\hline \multicolumn{2}{|c|}{ PHASE 3 Removing the gallbladder (Operation phase) } \\
\hline $\begin{array}{l}\text { Handling of the instruments (correct and } \\
\text { safe use of the instruments) } \\
\text { Explaining the visual sightings: tips on the } \\
\text { appearance and forms of tissues; } \\
\text { promoting the ability to distinguish } \\
\text { between different kinds of tissues and } \\
\text { structures possibly mutilated by former } \\
\text { infections } \\
\text { Identification of structures involving } \\
\text { special risk } \\
\text { Dissection of the anatomical structures in } \\
\text { the optimal and safest way } \\
\text { Use of clipping instruments } \\
\text { Dissecting the gallbladder from the } \\
\text { hepatic bed, inspecting the hepatic bed for } \\
\text { blood or bill leaks, removing the } \\
\text { gallbladder }\end{array}$ & $\begin{array}{l}\text { Selecting the instruments to be used (the most suitable } \\
\text { instruments for the operation, and sharing their use between team } \\
\text { members) } \\
\text { Ensuring good visibility (various factors affecting visibility) } \\
\text { The use of grasper instruments, plus techniques to ensure good } \\
\text { visibility } \\
\text { Description, reflection on, and assessment of the selected cutting } \\
\text { and dissection method, as compared to other options } \\
\text { Performing a cholangiography when necessary } \\
\text { Clipping (safety and optimal installation of the clips) } \\
\text { Safe cutting and use of current (diathermia) } \\
\text { Principles of operating when problems or emergencies occur } \\
\text { (problem solving and solutions, teamwork) } \\
\text { Alternative ways of removing the gallbladder (changing to open } \\
\text { surgery techniques, etc.) } \\
\text { Minimizing the risk of infection } \\
\text { The risks from different methods }\end{array}$ \\
\hline \multicolumn{2}{|c|}{ PHASE 4 Final check and closure of the incisions } \\
\hline $\begin{array}{l}\text { Inspecting and preparing for potential } \\
\text { damage to the abdominal cavity and its } \\
\text { organs } \\
\text { Dealing with any bleedings }\end{array}$ & $\begin{array}{l}\text { Inspecting the operating field } \\
\text { Removing blood, bile, and other fluid accumulations, rinsing of } \\
\text { the abdominal cavity } \\
\text { Removing trocars under visual control (checking for bleeding) } \\
\text { Closing the incisions }\end{array}$ \\
\hline
\end{tabular}


Analysis of the data showed that guidance related to risks and potential errors concentrated mainly on the operating phase (3), involving the removal of the gallbladder (see Table 4). By contrast, very few potential errors or risks were addressed in the previous phases, namely (1) preparing for the operation, and (2) creating the pneumoperitoneum and placing the trocars. Nevertheless, these phases can be considered to be crucial as the operation phase itself, since they lay the foundation for the whole procedure, and thus for the success and safety of the operation. A focus primarily on operating phase (3) was most clearly manifested in the case of a trainer who left the OT at the end of phase (3), leaving the trainee alone to complete phase 4 (comprising the final check and closure of the incisions). This might give the trainee a hidden - and erroneous - signal that the entire surgical operation was completed after the actual operating phase.

Table 4. Amount of the risks and possible errors identified and not identified in the guidance within the four phases of the five LAP chole operations

\begin{tabular}{lccc} 
& $\begin{array}{c}\text { Identified in } \\
\text { the guidance }\end{array}$ & $\begin{array}{c}\text { Not identified } \\
\text { within the } \\
\text { guidance }\end{array}$ & Total \\
\hline Phase 1 & 1 & 6 & 7 \\
Phase 2 & 2 & 9 & 11 \\
Phase 3 & 6 & 11 & 17 \\
Phase 4 & 2 & 4 & 6 \\
\hline Total & 11 & 30 & 41
\end{tabular}

The guidance that was given mostly concerned technical issues such as instrument handling, and exploration of the most critical anatomical structures. In describing the videotaped medical operation, the consultant surgeon said the following:

"the trainer recognizes the problem with gas flow and begins to sort it out with the scrub nurse. This problem with gas flow seems not to be noticed by the trainee who is totally occupied by his work with the trocars".

It seemed that amid the stress and pressure of conducting the surgical procedure, the trainers had difficulties in expressing their thoughts and explicating their problem-solving processes. In some cases, the trainee and the trainer changed their 
operating roles, and the trainer became more like an observer. However, the roles assigned, and the demonstrations of the challenges were not always clear; more verbal explanations and direct guidance would have been needed to promote the trainee's learning. Moreover, most of the potential error and risk situations were not addressed. For example, at the start of the operation no guidance was given on certain important aspects of safe operating, including (i) ergonomics, (ii) task division for teamwork, (iii) the trainee's previous knowledge and skills, or (iv) planning for the unexpected. Nor was there mention of (v) alternative ways of operating, (vi) operating in difficult situations, or (vii) identifying ways to decrease these difficulties. In assessing the original recordings, the consultant surgeon noted these missing acts of guidance as follows: "the trocars get placed in the middle of these adhesion fields. Neither the trainer nor the trainee seems to notice the adhesions and how well the trocars fit in (see also table 1)". These are all undoubtedly important issues for surgical learning.

In relation to our second research question, (regarding which risks and potential errors should be addressed during authentic operations, and which can be learned outside the operating theater), all the risks and potential errors $(n=110)$ identified within the five operations were categorized into two categories. This categorization takes into account the learning options and training facilities available in the hospital in question.

The categorization indicated that most of the risks and potential errors $(80 \%)$ should be considered prior to practical training in the OT. In fact, training outside the OT would be possible for most technical skills. These would include the handling of instruments, the functions of the instruments, working within a two-dimensional view, ergonomics-related issues, knowledge of different operation phases for the safe conduct of the operation, patient- and pathology-related matters, learning goals, and a structure to enable these. Conversely, $20 \%$ of the risks and potential errors should indeed be addressed in practical training within an authentic operation. The risks and errors here are interwoven with the patient's individual anatomy, the patient's pathology, unexpected procedural challenges, teamwork and collaboration, and practical decisions concerning the safe conduct of the operation. It is true that all surgical skills need to be fine-tuned with real patients and real operations. Nevertheless, there are good grounds for suggesting that the OT is not a place for practicing basic surgical skills such as the naming and handling of instruments. 


\section{DISCUSSION}

Despite the small number of the analyzed surgical operations, our findings showed that within the authentic surgical laparoscopic operations, risks/errors were rarely addressed in the guidance given by the trainer (the senior surgeon). The guidance concentrated mostly on the operation phase. Thus, preparatory phases critical for the safety and success of the whole operation were mostly ignored. The main aspects considered in the guidance involved technical issues such as instrument handling, and the patient's anatomical characteristics. The trainee's attention was not drawn to the risks and potential errors emerging from characteristics specific to the patient. There was also a lack of guidance on team working, dealing with unexpected challenges, or alternative ways of operating. In addition, the trainers did not explicate their own decision making or problem solving. However, this kind of tacit knowledge - if spoken aloud - could be extremely valuable for trainee learning in authentic situations. The instructional interaction did not include reflection on the present experience or root-case analyses of the risks and potential errors. It has been suggested that doing this promotes learning from errors (Bauer and Mulder, 2007).

In the expert evaluation, nearly all the risk situations recognized in previous studies (Silvennoinen et al., 2015) were also recognized by our expert. From the perspective of patient safety, these observations raise serious concerns. Given the lack of attention to teamwork, the trainer's reactions, and the lack of verbal communication, there appeared to be clear signs of stress and heavy concentration. All these had the potential to affect the quality of the operation and of communication within the operating team. It is notable that some of the risks and potential errors in one specific operating phase (gallbladder dissection) resulted from shortcomings in the previous phases of the operation. This would imply that the entire training program should be designed in such a way as to set the assessment of risks and errors as a learning objective. Consequently, most issues would be addressed before the authentic operation. By contrast, practice-based guidance could focus more on situation-specific matters and on teamwork. This would also have the potential to enhance safety, since this would decrease the trainer's workload. In addition, confronting a trainee with all the risks possible during an operation (as it is a complex situation) may lead to cognitive overload of the trainee as well. Instead, it may be more reasonable to present only a subset of possible risks at a time. 
Our study confirms the findings of others, i.e. that there is a need for advanced strategies of training and curriculum development, including stronger pedagogic thinking (Billett, 2016; Gowlland, 2014; Sutkin and Zukas, 2014a, 2014b). Surgical training by the apprenticeship model, and permitting the trainee to be a responsible part of a surgical team, can be an effective method for developing the trainee's professional skills. However, as revealed by this study, if this method has no systematic structure for guidance -other than merely following basic procedural phases -, many learning possibilities will be missed. To support influential guidance, a systematic evidence-based guidance structure should be designed in relation to operation's critical steps. In part, these critical steps will encompass known risks and potential errors. These should be recognized in advance and taken into account during the operation (Beckett and Gough, 2004; Kilminster and Zukas, 2005; Silvennoinen et al., 2015).

As suggested in the theoretical notions of experiential and transformative learning, reflective practitioner, and deliberate practice, the role of reflection should be emphasized in the guidance of practical training. To facilitate learning from errors, reflection should focus especially on the provision of detailed anticipatory knowledge about the possible errors and risks to be avoided. In addition, reflection on guidance interaction should focus on procedural knowledge concerning alternative methods of completing an operation, interpretation of situational cues and perceptions, and problem solving concerning the root-causes of procedural decisions. In the context of guidance interaction, such reflection should be understood as shared reflection that takes place in dialogue between the trainer and trainee.

Teaching in authentic surgical operations can pose a challenge for the trainer. The trainer is in charge of the operation and has to be constantly alert in case the trainee runs into trouble. This study indicated that the total number of potential failures in an operation can be high, an aspect that adds to the cognitive workload of the trainer surgeon (El Bardissi and Sundt, 2012). However, if the critical steps, including possible risks and errors, were systematically trained for in advance, the mental workload might become more manageable. It seems reasonable to suppose that reducing the cognitive workload of the surgical team would enhance the overall safety of the operation.

This study contributes to an understanding of issues that need to be addressed when 
training is conducted by the traditional - and in some ways, highly valuable apprenticeship method. In particular, risk management and avoidance of human error are central elements in securing patient safety. The study also underlines the need for more guidance skills for both trainers and trainees, if practice-based learning opportunities are to be utilized optimally. As a practical outcome, the findings could contribute to the development of a more universal, pedagogically powerful training strategy, including a strong emphasis on risks and potential errors. For the surgical trainee, participation as a team member in a surgical operation is an excellent opportunity to learn, to practice operation skills, and to build up expertise. However, in pursuing these objectives, patient safety must never be compromised. The procedural phases of authentic surgical operations form a basic learning structure, but a deeper understanding of operation safety needs a more systematic and carefully-planned learning environment; it thus requires an instructional system which will utilize the entire hospital context and all available facilities for learning. Procedure-related risks comprise a natural part of the fuller picture, in conjunction with a more comprehensive educational strategy.

A training curriculum based on potential risks and errors could also be utilized in the quality management of surgical operations. If a complication happens, it could be reported and analyzed by the instructional structure used in the training program. This connects the procedure to the results and patients' recovery and aids in further learning about everyday patient work. This also facilitates further development of the training curriculum. Developing /learning such anticipatory knowledge on avoidable errors is vital in medical education in order to guarantee patient safety, a major goal in medicine (Aspden et al., 2004). In practical medical learning settings, avoidable errors are present as risks and possible errors. These should be supported by instructional activities and guidance during medical operations that take place in authentic situations.

It is worth noting that many of the learning objectives concerning risks and errors observed in this study could be addressed in advance via simulators. Nevertheless, the need for an optimal training program and for structured guidance remains the same, whether the context is one of a simulator or a real operation.

All operations have their own salient risks, and this has important implications for organizing authentic practice-based learning. The strengths and weaknesses of learning in 
authentic situations are related to the features of case-based learning more generally. This implies that there should be enough variety in individual patient cases for trainees to be able to manage a wide range of risk situations. Emphatically, this does not imply that factors related to cost-effectiveness should be ignored in the construction of learning environments for practice-based training. On the contrary, it suggests these factors may go hand-in-hand with optimal learning environments, and hence enhanced operative safety.

References:

Agresta, F., Campanile, F. C. and Vettoretto, N. V. (2014), Laparoscopic Cholecystectomy: An Evidence-Based Guide, Springer.

Antikainen, T., Silvennoinen, M. and Mecklin, J. (2010)," Complications related to cholecystectomies in 2005 - 2007: An analyses of cases judged by the Patient Insurance Centre in Finland”, Finnish Medical Journal, Vol. 65 No. 46, pp. 3777-3782.

Aspden, P., Corrican, J. M., Wolcott, J. and Erickson, S. M. (2004), Patient safety, National Academic Press, Washington, DC.

Bauer, J. and Gruber, H. (2007), "Workplace changes and workplace learning: Advantage of an educational micro perspective", International Journal of Lifelong Education, Vol. 26 No. 6, pp. 675-688.

Bauer, J. and Mulder, R. H. (2007), "Modelling learning from errors in daily work", Learning in Health and Social Care, Vol. 6 No. 3, pp. 121-133.

Bauer, J. and Mulder, R. H. (2008), “Conceptualisation of learning through errors at work - a literature review", In Billett, S., Harteis, C. and Eteläpelto, A. (Eds.), Emerging perspectives on learning through work, Sense, Rotterdam, pp. 115-128.

Beckett, D. and Gough, J. (2004), "Perceptions of professional identity: a story from paediatrics", Studies in Continuing Education, Vol. 26 No 2, pp. 195-208.

Billett, S. (2006), “Constituting the workplace curriculum”, Journal of Curriculum 
Studies, Vol. 38 Vol. 1, pp. 31-84.

Billett, S. (2016), "Learning through health care work: premises, contributions and practices", Medical Education, Vol. 50 Vol 1, pp. 124-131.

Blom, E. M., Verdaasdonk, E. G. G., Stassen, L. P. S., Stassen, H. G., Wieringa, P. A. and Dankelman, J. (2007), "Analysis of verbal communication during teaching in the operation room and the potentials for surgical training", Surgical Endoscopy, Vol. 21 No 9, pp. $1560-1566$.

Breckwoldt, J., Gruber, H. and Wittmann, A. (2014), “Simulation training”, In Billet, S., Harteis, C. and Gruber, H. (Ed.), International Handbook of Research in Professional and Practice-based Learning, Springer, New York, pp. 673-698.

Brown, V. and Clarke, V. (2006), "Using thematic analysis in psychology", Qualitative research in psychology, Vol. 3 No 2, pp. 77-101.

Catchpole, K., Giddings, A., De Leval, M., Peek, G., Godden, P., Utley, M., Gallivan, S., Hirst, G. and Dale, T. (2006), "Identification of system failures in succesful paediatric cardiac surgery", Ergonomics, Vol.49 No. 5-6, pp. 567-588.

Collins, A., Brown, JS. and Newman, SE. (1989), "Cognitive apprenticeship: Teaching the crafts of reading, writing and mathematics", In Resnicj, LB. and Hillsdale NJ. (Ed.), Knowledge, learning and instruction: Essays in honour of Robert Glaser, Erlbaum, pp. 453-494.

Dochy, F., Gijbels, D., Segers, M. and van der Bossche, P. (2011), Theories of learning for the workplace, Routledge, London.

Dornan, T. and Teunissen, PW. (2014), “Medical Education”, In Billet, S., Harteis, C. and Gruber, H. (Ed.), Handbook of Research in Professional and Practice-based Learning, Springer, New York, pp. 561-590.

El Bardissi, AW. and Sundt, TM. (2011), "Human factors and operating room safety", Surgical Clinics of North America, Vol. 92 No.1, pp. 21-35.

Ericsson, K. A. (2006), "The influence of experience and deliberate practice on the 
development of superior expert performance". In Ericsson, K. A., Charness, N., Feltovich, P. J. and Hoffman, R. R. (Ed.), The Cambridge handbook of expertise and expert performance, Cambridge University Press, Cambridge, pp.683-704.

Fried, GM., Feldman, LS. and Klassen, DR. (2005), "Cholecystectomy and Common Bileduct Exploration”, In Fink, MP., Jurkovich, GJ., Kaiser, LP., Pearce, WH., Pemberton, JH., Soper, NJ. and Souba, WW. (Ed.), ACS Surgery: principles \& practice, $6^{\text {th }}$ edn. Decker Publishing, pp. 729-251.

Gartmeier, M., Jonasson, C. and Solomou, M. (2017), "Negative Knowledge in Virtual and Game-Based Environments", In Ariso, J.M. (Ed.), Augmented reality-Reflection on Its Contribution to Knowledge Formation, Walter de Gruyter GmbH, Berlin/Boston, pp. 217-234.

Gowlland, G. (2014), “Apprenticeship as a Model for Learning in and Through Professional Practice“, In Billet, S., Harteis, C. and Gruber, H. (Ed.), International Handbook of Research in Professional and Practice-based Learning, Springer, New York, pp. 759-780.

Harteis, C. and Bauer, J. (2014), "Learning from Errors at Work”, In Billet, S., Harteis, C. and Gruber, H. (Ed.), International Handbook of Research in Professional and Practice-based Learning, Springer, New York, pp. 699-732.

Ingold, T. (2000), The perception of the environment: Essays on livelihood, dwelling and skill, Routledge, London.

Jänes, A. (2006), Clipless Laparoscopic Cholecystectomy with Harmonic, Euromed Communications, UK.

Kilminster, S. and Zukas, M. (2005), "Learning, life and death: theorising doctors' learning through the supervisory relationship", In Boud, D. (Ed.), Researching work and learning conference, University of Technology, Sydney.

Kolb, DA. (1984), Experiential learning: Experience as the source of learning and development, Englewood Cliffs, NJ, Prentice-Hall. 
Koskela, I. and Palukka, H. (2011), "Trainer interventions as instructional strategies in air traffic control training", Journal of Workplace Learning, Vol. 23 No. 5, pp. 293 - 314.

Lave, J. and Wenger, E. (1991), Situated learning: Legitimate peripheral participation, Cambridge University Press, New York.

Mezirov, J. (1991), Transformative dimensions of adult learning, Jossey-Bass, San Francisco.

Naweed, A. and Ambrosetti, A. (2015), "Mentoring in the rail context: The influence of training, style, and practice", Journal of Workplace Learning, Vol. 27 No. 1, pp. 3-18.

Park, J., Woodrow, SI., Reznick, RK., Beales, J. and MacRae, HM. (2010), “Observation, reflection and reinforcement: surgery faculty members' and residents' perceptions of how they learned professionalism", Academic Medicine, Vol. 85 No. 1, pp. 134-139.

Patton, M. (2002), Qualitative research \& evaluation methods, Sage Publications, Thousand Oaks, CA.

Ruoranen, M., Collin, K., Paloniemi, S. and Eteläpelto, A. (2013), "Challenges for surgical trainees' practice-based learning”, In Higgs, J., Sheehan, D., Baldry-Currens, J., Letts, W., Jensen, G. (Ed.), Realizing exemplary practice-based education, Sense Publisher, Rotterdam, pp. 101-110.

Schön, D. A. (1983), The reflective practitioner: How professionals think in action, Temple Smith, London.

Sheehan, D. and Higgs, J. (2013), "Practice-based education: Theoretical underpinnings", In Higgs, J., Sheehan, D., Currens, JB., Letts, W. and Jensen, GM. (Ed.), Realizing Exemplary Practice-based Education, Sense Publishers, Rotterdam, pp. $13-24$.

Silvennoinen, M., Antikainen, T. and Mecklin, J-P. (2015), "Video-assisted surgery: suggestions for failure prevention in laparoscopic cholecystectomy", Cognition, Technology \& Work, Vol. 17 No. 1, pp. 145-155.

Smith, C., Varkey, A., Evans, AT. and Reilly, BM. (2004), "Evaluating the performance 
of inpatient attending physicians: A new instrument for today's teaching hospitals", Journal of General Internal Medicine, Vol. 19 No. 7, pp. 766-771.

Spaan, N., S., Dekker, A., Velden. A. and Groot, E. (2015), ’Informal and formal learning of general practitioners", Journal of Workplace Learning, Vol. 28 No. 6, pp. 378-391.

Sutkin, G., Littleton, EB. and Kanter, SL. (2014a), "How Surgical Mentors Teach: A Classification of In Vivo Teaching Behaviours, Part 2: Physical Teaching Guidance”, Journal of Surgical Education, http://dx.doi.org/10.1016/j.jsurg.2014.10.004

Sutkin, G., Littleton, EB. and Kanter SL. (2014b), "How Surgical Mentors Teach: A Classification of In Vivo Teaching Behaviours, Part 1: Verbal Teaching Guidance", Journal of Surgical Education,

http://dx.doi.org/10.1016/j.jsurg.2014.10.003

Tucker, A. L. and Edmonson, A. C. (2003), Why hospitals don't learn from failures: Organisational and psychological dynamics that inhibit system change. California Management Review, Vol. 45 No. 2, pp. 55-72.

Tynjälä, P. and Newton, JM. (2014), “Transition to working life: Securing Professional Competence”, In Billett, S., Harteis, C. and Gruber, H. (Ed.), International handbook of research in professional and practice-based learning, Springer, London, pp. 513-534. Weddle, A. B. and Holland, J. D. (2010), "Professional perception and expert action: Scaffolding embodied practices in professional education", Mind, Culture, and Activity, Vol. 17 No. 2, pp. 119-148.

Wenger, E. (1998), Communities of practice. Learning, meaning and identity, Cambridge university press. 